\title{
Avaliação de Ações e Números Contábeis: Aplicação dos Modelos Zhang (2000) e Zhang \& Chen (2007) no Mercado Brasileiro
}

\author{
Fernando Caio Galdi* \\ Rodrigo Falco Lopes**
}

Resumo

Este artigo investiga a relação entre os números contábeis e os retornos das ações no mercado brasileiro. Para isso baseia-se no modelo teórico desenvolvido por Zhang (2000) e no modelo empírico de Zhang \& Chen (2007). Os modelos demonstram que o retorno das ações pode ser escrito como função das seguintes variáveis: lucro líquido, variação da rentabilidade, capital investido, variação da oportunidade de crescimento e taxa de desconto. De maneira geral os resultados empíricos encontrados no mercado brasileiro são condizentes com as relações descritas pelo modelo teórico, similarmente às relações encontradas no mercado norte-americano. A proximidade dos resultados e dos coeficientes estatísticos obtidos nos diferentes testes (pooled, Fama-Macbeth e dados em painel) suportam a robustez dos resultados.

Palavras-chave: retorno de ações; variáveis contábeis; avaliação de empresas.

Códigos JEL: M41; G14.

\section{Abstract}

This paper investigates how accounting variables explain cross-sectional stocks returns in Brazilian capital markets. The analysis is based on Zhang (2000) and Zhang \& Chen (2007) models. These models predict that stock returns are a function of net income, change in profitability, invested capital, changes in opportunity growths and discount rate. Generally, the empirical results for the Brazilian capital market are consistent with the theoretical relations that models describe, similarly to the results found in the US. Using different empirical tests (pooled regressions, Fama-Macbeth and panel data) the results and coefficients remain similar, what support the robustness of our findings.

Keywords: stock return; accounting variables; equity valuation.

Submetido em agosto de 2010. Aceito em dezembro de 2010. O artigo foi avaliado segundo o processo de duplo anonimato além de ser avaliado pelo editor. Editor responsável: Newton Costa Jr.

*Fundação Instituto Capixaba de Pesquisa em Contabilidade, Economia e Finanças, Vitória, Brasil. E-mail: fernando.galdi@fucape.br

**Fundação Instituto Capixaba de Pesq. em Contabilidade, Economia e Finanças, Vitória, Brasil. E-mail: falco_lopes@hotmail.com 


\section{Introdução}

A relevância dos números contábeis no processo de avaliação de empresas é abordada em trabalhos acadêmicos publicados tanto no Brasil quanto no exterior. Durante a década de 60, os trabalhos de Ball \& Brown (1968) e Beaver (1968) foram os primeiros a abordar a relação entre as informações contábeis e os preços das ações. Esses trabalhos foram pioneiros na chamada abordagem positiva na pesquisa em contabilidade. A partir de então, a contabilidade ganhou um novo foco e passou a ser vista como fonte de informação para o mercado, sendo analisada dentro do paradigma econômico tradicional e não mais isoladamente.

Penman (2007) apresenta diferentes métodos de avaliação de ações que utilizam como input números contábeis, tais como: avaliação por múltiplos, avaliação por lucros residuais (Residual Income Valuation) e avaliação com base no crescimento anormal dos lucros (Abnormal Earnings Growth).

Palepu et al. (2004) também destacam a relevância das variáveis contábeis em seu modelo proposto para avaliação de empresas, que consiste em quatro etapas: avaliação estratégica, avaliação contábil, avaliação financeira e avaliação prospectiva. Na análise contábil, é realizada uma avaliação da qualidade contábil por intermédio da avaliação das políticas e das estimativas contábeis. Na avaliação financeira, é realizada a análise dos demonstrativos contábeis ou a análise de balanços, objetivando identificar o desempenho histórico da empresa por meio de índices e de indicadores.

No contexto da investigação da utilidade das informações contábeis e de sua relação com o valor das empresas, surgiram diversos estudos empíricos e modelos teóricos sobre o tema. Entre eles, estão os modelos teóricos desenvolvidos por Zhang (2000) e os testes empíricos de Zhang \& Chen (2007) para o mercado americano. O modelo proposto leva em consideração não somente o lucro, mas também a rentabilidade, o capital investido, a oportunidade de crescimento e a taxa de desconto. Zhang \& Chen (2007) utilizaram técnicas econométricas para comparar os modelos propostos e os modelos tradicionais baseados em lucro. Os resultados encontrados no mercado americano apontam que o modelo desenvolvido por Zhang (2000) e testado por Zhang \& Chen (2007) possui maior poder explicativo que o modelo baseado somente nos lucros.

Este artigo tem como objetivo principal analisar a relevância das informações contábeis no retorno das ações no mercado brasileiro, de acordo com o modelo proposto e testado por Zhang \& Chen (2007) no mercado norte-americano. Com isso, serão analisados os resultados encontrados no mercado brasileiro, de forma a avaliar se as diferenças entre os ambientes institucionais nos quais operam os mercados de capitais brasileiro e norte-americano podem refletir em diferentes níveis de relevância das variáveis contábeis como fatores que explicam o retorno das ações.

Acredita-se que a aplicação desse modelo torna-se relevante devido ao fato de que suas relações empíricas são oriundas de uma fundamentação teórica que relaciona as informações financeiras à variação do retorno das ações. Considerando 
as afirmações de Beaver (1998) sobre a pouca eficiência ${ }^{1}$ dos mercados emergentes em relação às informações contábeis, este estudo visa contribuir com a literatura demonstrando de maneira consistente que determinadas variáveis apresentam relacionamento com o retorno das ações e, portanto, deveriam ser consideradas como fundamentais no processo estimação do valor das empresas. Quanto às diferenças entre os mercados, Galdi (2008) enfatiza que a análise da utilidade das demonstrações contábeis de empresas atuantes no mercado brasileiro torna-se um exercício interessante de ser investigado e comparado com resultados encontrados em outros países.

Sarlo (2004) destaca que as informações contábeis para atingir seus objetivos e realizar as suas atividades como meio de informação devem estar inseridas em um determinado ambiente. Dessa forma, é importante conhecer esse ambiente, sua estruturação, sua forma social, econômica, política, comercial e jurídica.

Dentre as características que diferenciam o mercado brasileiro do mercado norte-americano onde o modelo foi previamente testado podem-se destacar:

(i) A estrutura legal baseada no direito codificado (code law) - Este modelo adotado no Brasil, valoriza mais a forma em contraposição a essência dos fatos econômicos (Lopes, 2005). Diferentemente, o modelo common law adotado nos Estados Unidos, Reino Unido e outros países anglos saxões, apresenta estruturas gerais e menos regulamentadas. A literatura documenta alguns efeitos diferenciados em países nessas estruturas. Como exemplo, pode-se citar o trabalho de Pincus et al. (2007) que mostra evidencias de que a anomalia dos accruals ocorre principalmente em países que adotam o regime common law e não em países com o regime code law;

(ii) Emissão da normatização contábil pelo governo ou órgãos ligados ao governo: Lopes (2005) relatam que no Brasil existe uma grande influência do governo ou órgãos ligados ao governo nas normas contábeis. Segundo Galdi (2008), a normatização contábil das Sociedades Anônimas no Brasil é dada originalmente pela Lei 6.404/76 (Lei das S/A), recentemente complementada e alterada pela Lei 11.638/07 e Lei 11.941/09, cabendo à CVM (Comissão de Valores Mobiliários) normatizar assuntos específicos para as companhias abertas. O autor ressalta que o processo de normatização da contabilidade brasileira diferia consideravelmente dos países anglo-saxões até o ano de 2008. Galdi (2008) ainda lembra que outro ponto relevante sobre a influência governamental na qualidade contábil no período analisado se refere à atuação da Secretaria da Receita Federal (SRF). Todas as empresas brasileiras devem seguir as normas da SRF para a apuração e recolhimento dos impostos. Muitas vezes a influência das leis fiscais nos procedimen-

${ }^{1}$ Fama (1970) classificou a eficiência do mercado em forte, semiforte e fraca, de acordo com o nível de reconhecimento das informações disponíveis no preço das ações. Segundo ele, a forma forte reflete todas as informações relevantes disponíveis, públicas ou privadas; a forma semiforte reflete todas as informações publicamente disponíveis; e a forma fraca, somente informações do passado. 
tos contábeis distorciam a realidade econômica das empresas. Finalmente o mesmo autor lembra que já houve casos de intervenção governamental de maior escala, como a ocorrida no episódio da maxidesvalorização do Real em 1999. Naquele ano, o Ministério da Fazenda autorizou o diferimento das perdas com a variação cambial (este procedimento não era permitido sob as regras da CVM, que abriu exceção para este episódio específico). Conforme apresentado em Ali e Hwang (2000) as características apontadas tendem a reduzir a relevância dos números contábeis no Brasil;

(iii) Concentração de capital: A literatura aponta que a concentração acionária funciona como substituta para mecanismos de governança para um ambiente de pouca proteção aos investidores (Shleifer \& Vishny, 1997), considerandose que diminuí o conflito de agência. De acordo com dados do Economatica (Gazeta Mercantil, 2000), identificou-se que 95\% das empresas das brasileiras listadas na Bovespa possuem três ou menos acionistas com mais de $50 \%$ direitos de voto, fato que pode levar a uma perda de relevância da contabilidade como quebra da assimetria informacional (Galdi \& Lopes, 2007);

(iv) Baixo nível de enforcement: Durnev \& Kim (2005) citam em seu trabalho o baixo nível de enforcement do mercado brasileiro;

(v) Fontes de financiamento: Historicamente as empresas brasileiras não dependem do mercado de capitais para financiar suas atividades. ${ }^{2}$ A Tabela 2 apresentada por La Porta et al. (1997, p.1138), mostra isto. O Brasil tem um índice de capitalização externa em relação ao PNB de 0,18 enquanto este índice é de 0,58 nos Estados Unidos. O número de empresas listadas em Bolsa em relação à sua população também era bastante baixo no Brasil em 1994. Este indicador era 3,48 em relação a 30,11 nos Estados Unidos. Entre 1986 e 1996 não houve nenhuma oferta pública primária de ações no Brasil. A literatura indica que países que possuem fonte de financiamento advindo do mercado de capitais tendem a possuir modelos de evidenciação mais transparentes. Ali \& Hwang (2000) identificaram que as informações contábeis possuem menor relevância em países onde a fonte de capital está concentrada em bancos.

Neste estudo pretende-se verificar qual a relevância das variáveis contábeis como fonte de informação no retorno das ações negociadas na Bolsa de Valores de São Paulo (BOVESPA) de acordo com os modelos propostos por Zhang (2000) e Zhang \& Chen (2007). Partimos da hipótese de que as variáveis contábeis apresentadas no modelo teórico apresentam relação com o retorno das ações em um

\footnotetext{
${ }^{2}$ A partir de 2004 as empresas brasileiras passaram a acessar mais constantemente o mercado de capitais. Houve um salto na captação via emissão de ações de $\mathrm{R} \$ 230$ milhões no ano de 2003 para mais de $\mathrm{R} \$ 25$ bilhões no ano de 2007. Contudo os números ainda são mais baixos do que em países com mercado de capitais desenvolvidos.
} 
mercado com características específicas como o Brasil. Para essa investigação, testa-se a hipótese de que os retornos das ações negociadas na BOVESPA não podem ser explicados por variáveis contábeis conforme o modelo proposto por Zhang \& Chen (2007).

\section{Referencial Teórico}

De acordo com Zhang \& Chen (2007), um dos grandes propósitos da contabilidade é ajudar investidores a prever o fluxo de caixa futuro das empresas. Se as informações contábeis são informativas sobre os valores fundamentais e têm seus valores alterados, elas podem se correlacionar com a variação dos preços das ações.

O modelo de avaliação de empresas desenvolvido por Zhang (2000), e posteriormente aperfeiçoado por Zhang \& Chen (2007), é construído com base em opções reais e fornece uma representação contábil específica de acordo com a estabelecida noção da literatura de finanças de Miller \& Modigliani (1961) de que a firma consiste no valor de seus ativos atuais mais oportunidades de crescimento. O modelo em questão mostra que o valor da empresa é igual à capitalização dos lucros provenientes dos ativos existentes mais o valor das opções reais que surgem da flexibilidade de ajustes nas tomadas de decisão de investimentos pelo abandono ou opção por crescimento.

Segundo Zhang \& Chen (2007), o modelo proposto difere dos modelos baseados em lucros por algumas razões mencionadas a seguir:

- O modelo assume que as firmas tomam decisões racionais, optando somente por projetos que apresentam valor presente líquido positivo e realizam expansões apropriadas.

- Os modelos baseados na capitalização de lucros, os quais consideram as variações no lucro um fator explicativo, são mais apropriados para firmas que operam em um estado estacionário de crescimento. Nesse cenário, os lucros atuais são representações de lucros futuros. Esse fato decorre da consideração de que as firmas possuem uma rentabilidade diferente, com isso, o capital investido implicará diferentes resultados obtidos.

- O modelo incorpora uma maior quantidade de informações contábeis, promovendo uma visão mais completa de como os retornos das ações estão relacionados com as informações financeiras.

\subsection{Desenvolvimento do modelo proposto}

Zhang \& Chen (2007) iniciam a demonstração do modelo definindo o valor da empresa como o valor presente do fluxo de caixa futuro e, em seguida, equacionam os valores contábeis observáveis com o fluxo de caixa futuro, baseado em um padrão de avaliação de empresas já apresentado na literatura de finanças por autores como Penman (2007), Ohlson (1995) e Feltham \& Ohlson (1995, 1996). 
O modelo considera que o valor da empresa é uma função de dois atributos operacionais básicos: escala e rentabilidade, e que o processo de avaliação de empresas concentra-se na previsão futura dessas variáveis. A rentabilidade $-R e$ turn on Equity (ROE) (retorno sobre o patrimônio líquido) - apresenta um papel importante no modelo, pois, além de medir a habilidade da firma de gerar valor ao capital investido, indica como a firma provavelmente vai ajustar o curso das movimentações operacionais futuras. O modelo de avaliação embute a criação de valor gerado pelas decisões de investimento de capital pelas firmas de acordo com a disponibilidade de opções de crescimento, redução ou abandono. Na literatura de finanças, as opções reais como parte do valor da firma são reconhecidas por autores como Meyers (1977), Berger et al. (1996), Brennan \& Schartz (1985) e Berger et al. (1996) e na literatura contábil por Burgstahler \& Dichev (1997).

A versão simplificada do modelo é apresentada na equação (1). Onde:

$$
V_{t}=k E\left(X_{t+1}\right)+B_{t} P\left(q_{t}\right)+B_{t} g_{t} C\left(q_{t}\right)
$$

onde $V_{t}$ : é o valor da firma em $t$ (fim do período $t$ );

$B_{t}$ : é o patrimônio líquido em $t$;

$X_{t}$ : lucro gerado no período $t$;

$g_{t}$ : oportunidade de crescimento percebida em $t$, definido como o percentual ao qual a escala das operações (capital investido) pode crescer.

$q_{t}=X_{t} / B_{t-1}$ : rentabilidade (ROE) no período $t$

$E\left(X_{t+1}\right)$ : Expectativa de lucro no próximo período gerado pelos ativos atuais; $k$ : é o fator de capitalização dos lucros; $P\left(q_{t}\right)$ : Opção de venda para abandonar as operações, normalizada pela escala das operações $\left(B_{t}\right) ; C\left(q_{t}\right)$ : Opção de compra para expandir as operações, normalizada pela escala das operações $\left(B_{t}\right)$

O valor oriundo das opções e seus exercícios são funções probabilísticas. Intuitivamente a equação (1) mostra que o valor de mercado é igual à capitalização dos lucros dos ativos existentes mais o valor oriundo das opções de crescimento ou abandono. A rentabilidade $\left(q_{t}\right)$ e a oportunidade de crescimento $\left(g_{t}\right)$ são relevantes componentes que diferenciam o modelo.

Para simplificar a análise, assume-se que a rentabilidade possui um comportamento randômico, $q_{t+1}=q_{t}+e_{t+1}$, no qual $e_{t+1}$ é um termo de distúrbio de média zero. Então $E_{t}\left(X_{t+1}\right)=E_{t}\left(B_{t} q_{t+1}\right)=B_{t} q_{t}$, e $k=1 / r_{t}$, no qual $r_{t}$ é a taxa de desconto em $t$. Com isso, a função (1) torna-se:

$$
V_{t}=B_{t}\left[q_{t} / r_{t}+P\left(q_{t}\right)+g_{t} C\left(q_{t}\right)\right] \equiv B_{t} v\left(q_{t}, g_{t}, r_{t}\right)
$$

em que $v\left(q_{t}, g_{t}, r_{t}\right) \equiv q_{t} / r_{t}+P\left(q_{t}\right)+g_{t} C\left(q_{t}\right)$.

De acordo com a equação (2), o patrimônio líquido pode ser visto como o produto de dois elementos básicos: o montante de capital investido (patrimônio líquido), $B_{t}$, e o valor por unidade de capital, $v$, o qual é uma função probabilidade da rentabilidade $\left(q_{t}\right)$, oportunidade de crescimento $\left(g_{t}\right)$, e taxa de desconto $\left(r_{t}\right)$. 
Zhang (2000) demonstra que $v$ é uma função crescente e convexa de $q_{t} \cdot{ }^{3} \mathrm{~A}$ flexibilidade para reduzir as operações quando a rentabilidade é baixa e aumentar as operações quando a rentabilidade é alta tornam a função valuation convexa em $\left(q_{t}\right)$. De acordo com o estudo, quando a rentabilidade é baixa, a firma limita suas perdas abandonando operações e diversificando a aplicação de recursos em alternativas. Quando existe uma maior rentabilidade, além de uma maior produtividade dos ativos, existe um aumento nas opções de crescimento, o que torna a firma mais valiosa. A função $v$ aumenta com as oportunidades de crescimento $g_{t}$, e seu efeito é concentrado principalmente em regiões de alta rentabilidade. A função $v$ decresce com a taxa de desconto $r_{t}$, devido impacto no fluxo de caixa.

Para derivar a função retorno, é considerada a mudança do valor do patrimônio líquido da data $t$ para a data $t+1$, o qual é denominado $\Delta V_{t+1}$. Adotando-se as alterações em ambos os lados de (2), obtém-se:

$$
\Delta V_{t+1} \approx \Delta B_{t+1} v\left(q_{t}, g_{t}, r_{t}\right)+B_{t}\left[v_{1} \Delta q_{t+1}+C\left(q_{t}\right) \Delta g_{t+1}+v_{3} \Delta r_{t+1}\right]
$$

em que $v_{1}=d v / d q_{t}, v_{3}=d v / d r_{t}$ e $d v / d g_{t}=C\left(q_{t}\right)$.

Sendo $D_{t+1}$ os dividendos pagos no período $t+1$, e o retorno das ações em $t+1 R_{t+1}$ igual a:

$$
\begin{aligned}
R_{t+1} & =\frac{\Delta V_{t+1}+D_{t+1}}{V_{t}} \\
R_{t+1} & =v\left[\frac{\Delta B_{t+1}}{V_{t}}\right]+v_{1}\left[\frac{B_{t}}{V_{t}} \Delta q_{t+1}\right]+C\left(q_{t}\right)\left[\frac{B_{t}}{V_{t}} \Delta g_{t+1}\right] \\
& +v_{3}\left[\frac{B_{t}}{V_{t}} \Delta r_{t+1}\right]+\frac{D_{t+1}}{V_{t}} \\
R_{t+1} & =\frac{\Delta B_{t+1}}{B_{t}}+v_{1}\left[\frac{B_{t}}{V_{t}} \Delta q_{t+1}\right]+C\left(q_{t}\right)\left[\frac{B_{t}}{V_{t}} \Delta g_{t+1}\right] \\
& +v_{3}\left[\frac{B_{t}}{V_{t}} \Delta r_{t+1}\right]+\frac{D_{t+1}}{V_{t}}
\end{aligned}
$$

A partir da clean surplus relation $(\mathrm{CSR}),{ }^{4} \Delta B_{t+1}=X_{t+1}-D_{t+1}$, temse $D_{t+1}=X_{t+1}-\Delta B_{t+1}$. Substituindo-se $D_{t+1}$ em (4), obtém-se a seguinte função de retorno para o período $t+1$.

\footnotetext{
${ }^{3}$ A convexidade demonstrada no modelo não considera a competitividade da indústria. Se considerada essa restrição, a alta rentabilidade de uma firma pode atrair novos entrantes para uma determinada indústria, implicando uma futura redução da rentabilidade, o que limita ou até elimina a convexidade da função.

${ }^{4}$ Clean surplus relation - Lucro limpo - quando todas as alterações ocorridas no patrimônio líquido necessariamente passam pelo resultado do período.
} 


$$
\begin{aligned}
R_{t+1} & =\left[\frac{X_{t+1}}{V_{t}}\right]+v_{1}\left[\frac{B_{t}}{V_{t}} \Delta q_{t+1}\right]+\left[\left(1-\frac{B_{t}}{V_{t}}\right) \frac{\Delta B_{t+1}}{B_{t}}\right] \\
& +C\left(q_{t}\right)\left[\frac{B_{t}}{V_{t}} \Delta g_{t+1}\right]+v_{3}\left[\frac{B_{t}}{V_{t}} \Delta r_{t+1}\right]
\end{aligned}
$$

A equação (5) mostra que o retorno das ações no período $t+1$ é uma função dos seguintes fatores: (i) lucro pelo valor da empresa $\left(X_{t+1} / V_{t}\right)$. (ii) variação da rentabilidade $\left(\Delta q_{t+1}\right)$, (iii) variação do patrimônio líquido $\left(\Delta B_{t+1} / B_{t}\right)$, denominado como capital investido, (iv) variação da oportunidade de crescimento $\left(\Delta g_{t+1}\right)$, e variação da taxa de desconto $\left(\Delta r_{t+1}\right)$.

\subsection{Fatores que impactam o retorno}

As variáveis utilizadas no modelo, assim como seus respectivos sinais, são apresentadas a seguir.

Lucro por ação $\left(X_{t+1} / V_{t}\right)$ : o lucro $X_{t+1}$ representa o valor gerado no período corrente $(t+1)$. O lucro normalizado pelo valor de mercado do início do período constitui parte do retorno das ações. De acordo com o modelo proposto (5), o coeficiente $\left(X_{t+1} / V_{t}\right)$ é positivo.

Variação da rentabilidade $\left(\Delta q_{t+1}\right)$ : considerando-se a rentabilidade como ponto central para a geração de valor, a variação na rentabilidade impacta diretamente o retorno. O modelo requer que $\Delta q_{t+1}$ seja ajustado pelo book-to-market $\left(B_{t} / V_{t}\right)$ do início do período, na função do modelo de retorno. Isso se deve ao fato de que as variações na rentabilidade afetam o valor gerado por meio de capital investido $\left(B_{t}\right)$, já que os retornos são definidos em relação ao valor de mercado $\left(V_{t}\right)$ do início do período. O coeficiente em $\left(\Delta q_{t+1}\right)$ (após o ajuste pelo bookto-market) é $v_{1}\left(d v / d q_{t}\right)$, a qual é uma função crescente de $q_{t}$ dado que $v$ é uma função crescente e convexa de $q_{t}$. Espera-se que o coeficiente de $\Delta q_{t+1}$ seja positivo para todos os níveis de rentabilidade.

Capital Investido $\left(\Delta B_{t+1} / B_{t}\right)$ : é definido como a proporção da variação do capital investido $\Delta B_{t+1} / B_{t}$. Afeta o retorno, pois altera a base de capital em que o valor é gerado. O modelo requer que $\Delta B_{t+1} / B_{t}$ seja ajustado por $\left(1-B_{t} / V_{t}\right)$ para refletir o fato de que o retorno relaciona-se com valor líquido criado a partir do capital investido acima e abaixo do custo de capital. Intuitivamente, um acréscimo de capital que derive de um incremento de capital aumenta as expectativas sobre o valor futuro gerado, e isso aumenta o valor de mercado da empresa. Entretanto o aumento de capital investido também reduz os dividendos do período. O coeficiente $\Delta B_{t+1} / B_{t}$ captura o resultado líquido desses dois efeitos. O modelo prevê para essa variável um coeficiente positivo, uma vez que, na média, as firmas apresentam valor presente líquido positivo de seus investimentos. 
Variação das oportunidades de crescimento $\left(\Delta g_{t+1}\right)$ : devido ao fato de o valor da empresa estar associado às oportunidades de crescimento, o retorno deve depender das variações das oportunidades de crescimento. Da mesma forma, uma oportunidade de crescimento incrementa o valor de mercado e, consequentemente, o retorno das ações. O impacto de $\Delta g_{t+1}$ no retorno deve ser maior para firmas com maior rentabilidade - capazes de explorar oportunidades externas. Segundo o modelo, $\Delta g_{t+1}$ também deve ser ajustado por $B_{t} / V_{t}$ pela mesma razão já explicada, anteriormente, para o capital investido. O coeficiente de $\Delta g_{t+1}$, após o ajuste por $B_{t} / V_{t}$, é $C\left(q_{t}\right)$, o qual é positivo e crescente em $q_{t}$.

Variação na taxa de desconto $\left(\Delta r_{t+1}\right)$ : a taxa de desconto determina como o fluxo de caixa futuro é precificado. Um aumento na taxa de desconto reduz o valor presente do fluxo de caixa futuro, o qual torna menor o valor da empresa e o retorno das ações. Portanto, o coeficiente previsto para a variação da taxa de desconto $\Delta r_{t+1}, v_{3}$ é previsto ser negativo.

\section{Metodologia}

Para a elaboração deste estudo foram utilizados dados obtidos por meio do banco de dados da Economatica. Entretanto, para obtenção da data de publicação das cotações das ações das empresas no ano $t$ medido 2 dias após a publicação do lucro (divulgação do balanço) do ano $t-1$ um dia após a publicação do lucro em $t$, foi realizada uma consulta no Sistema de Divulgação Externa disponível nos sites da BOVESPA e CVM, uma vez que o banco de dados do Economatica não dispõe dessa informação.

A análise possui observações de periodicidade anual de todas as empresas listadas na Bovespa (incluindo as instituições financeiras) entre o período de 1997 e 2008 (12 anos). O presente trabalho aplicou o procedimento de seleção da amostra similar à pesquisa realizada por Zhang \& Chen (2007) para obter maior comparabilidade dos resultados. Vale salientar que Zhang \& Chen (2007) utilizaram dados entre o período de 1983 e 2001 (19 anos).

As empresas que apresentaram valores negativos no patrimônio líquido (PL) foram excluídas devido a distorção nos indicadores que empresas com PL negativo podem trazer como, por exemplo, ROE positivo de empresas que apresentam prejuízo e PL negativo. Utilizando a metodologia de trimmed data, também foi aplicado um corte de 0,5\% nas observações das variáveis independentes que compõem a base de dados. Ressalta-se que no trabalho de Zhang \& Chen (2007), tanto o corte das observações com PL negativo quanto dos valores extremos foram também aplicados. Esse procedimento resultou em 1.678 observações comparando-se com 27.987 observações para o mercado americano. A tabela 1 apresenta o detalhamento do procedimento de seleção da amostra utilizada no artigo. 
Tabela 1

Composição da amostra utilizada no trabalho

\begin{tabular}{lc}
\hline Numero inicial de observações: & 2.123 \\
Observações com PL negativo: & 381 \\
Trimmed data: & 64 \\
Amostra final: & 1.678 \\
\hline
\end{tabular}

O primeiro modelo empírico que investiga a relação do retorno das ações e as variáveis contábeis é apresentado por meio da Equação 6.

$$
R_{i t}=\alpha+\beta x_{i t}+\gamma \Delta \hat{q}_{i t}+\delta \Delta \hat{b}_{i t}+\omega \Delta \hat{g}_{i t}+\varphi \Delta \hat{r}_{i t}+e_{i t}
$$

onde: $R_{i t}$ : é o retorno anual da firma $i$ no ano $t$. Esse é medido pela variação do valor da ação da empresa $i$ no ano $t$, medido 2 dias após a publicação do lucro (divulgação do balanço) do ano $t-1$ até um dia após a publicação do lucro em $t$. $x_{i t}=X_{i t} / V_{i t-1}$ : é o lucro da firma $i$ no ano $t$ dividido pelo valor de mercado da firma $i$ no ano $t-1$.

$\Delta \hat{q}_{i t}=\left(q_{i t}-q_{i t-1}\right) B_{i t-1} / V_{i t-1}$ : é a variação na rentabilidade da firma $i$ no ano $t$, ajustado pela razão patrimônio líquido e valor de mercado em $t-1$, sendo a rentabilidade $q_{i t}=X_{i t} / B_{i t-1}$ definida como o retorno sobre o patrimônio líquido. $\Delta \hat{b}_{i t}=\left[\left(B_{i t}-B_{i t-1}\right) / B_{i t-1}\right]\left(1-B_{i t-1} / V_{i t-1}\right)$ : é o patrimônio líquido (capital investido) ou mudança proporcional no patrimônio líquido da firma $i$ no ano $t$, ajustado por um menos o book-to-market em $t-1$.

$\Delta \hat{g}_{i t}=\left(g_{i t}-g_{i t-1}\right) B_{i t-1} / V_{i t-1}$ : é a variação da oportunidade de crescimento da firma $i$ no ano $t$, ajustado pelo book-to-market em $t-1$. Neste estudo, $g_{i t}=$ $V_{i t} / B_{i t}$, ou seja, foi utilizado o market-to-book ou price-to-book como proxy para crescimento. ${ }^{5}$

$\Delta \hat{r}_{i t}=\left(r_{i t}-r_{i t-1}\right) B_{i t-1} / V_{i t-1}$ : é a variação da taxa de desconto no ano $t$ ajustado pelo book-to-market em $t-1 \alpha, \beta, \gamma, \delta, \omega, \varphi$ : são os coeficientes da regressão; e $e_{i t}$ : é o termo residual

Os valores teóricos previstos para o modelo são: $\beta=1, \gamma>0, \delta=1, \omega>0$ e $\varphi<0$.

Uma segunda versão do modelo de retorno é a aplicação de uma regressão que considera a variação dos coeficientes de $\Delta \hat{q}_{i t}$ e $\Delta \hat{g}_{i t}$ em virtude dos diferentes níveis de rentabilidade e oportunidade de crescimento, devido às propriedades adotadas no modelo quanto a opções reais já demonstradas anteriormente na definição teórica do modelo.

O modelo pode ser observado a seguir:

$$
\begin{aligned}
R_{i t} & =\alpha+\beta x_{i t}+\gamma \Delta \hat{q}_{i t}+\gamma_{M} M \Delta \hat{q}_{i t}+\gamma_{H} H \Delta \hat{q}_{i t}+\delta \Delta \hat{b}_{i t} \\
& +\omega \Delta \hat{g}_{i t}+\omega_{M} M \Delta \hat{g}_{i t}+\omega_{H} H \Delta \hat{g}_{i t}+\varphi \Delta \hat{r}_{i t}+e_{i t}
\end{aligned}
$$

${ }^{5}$ Nesse estudo foi utilizada a variável market-to-book como proxy de crescimento ao invés do consenso dos analistas de mercado, pois esta informação não é existente para o mercado brasileiro no período analisado. 
Na equação (7) $M$ e $H$ são variáveis dummy para as diferentes rentabilidades, média (um terço médio) e alta (terça parte superior) da rentabilidade das amostras. Esses coeficientes representam um valor incremental para os valores de maior rentabilidade. Esperam-se assim melhores coeficientes para o modelo.

Os valores teóricos previstos para os coeficientes desse modelo são: $\gamma_{H}>$ $\gamma_{M}>0$ e $\omega_{H}>\omega_{M}>0$. Para os demais coeficientes, as previsões feitas para (6) são mantidas.

Para verificação da relevância dos modelos apresentados por Zhang \& Chen (2007), as duas regressões (6) e (7) serão testadas e comparadas entre elas e também com um modelo baseado em lucros (8) apresentado a seguir.

$$
R_{i t}=\alpha+\beta x_{i t}+\lambda \Delta x_{i t}+e_{i t}
$$

No qual $\Delta x_{i t}=\left(X_{i t}-X_{i t-1}\right) / V_{i t-1}$ é a variação do lucro da firma i no período $t$ dividido pelo valor de mercado em $t-1$.

O modelo (8) baseado em lucros é apresentado por autores como Easton \& Harris (1991), Ali \& Hwang (2000), Ely \& Waymire (1999), Francis \& Shipper (1999) e Lev \& Zarowin (1999).

\subsection{Principais resultados empíricos observados}

Neste item, são avaliados os resultados empíricos dos modelos propostos (6) e (7), e seus resultados são comparados com o modelo (8) baseado em lucros.

As amostras obtidas foram submetidas a diferentes testes estatísticos visando a avaliar a robustez dos modelos. O Item 4.1 apresenta os resultados submetidos à regressão em pooled, e também o teste de Vuong (1989) com o objetivo de comparar os modelos estudados. O item 5.2 apresenta os resultados submetidos à regressão em pooled segmentados anualmente, além da realização do teste em painel Fama-Macbeth para as amostras contendo todos os anos. O item 4.3 apresenta os resultados submetidos à técnica de dados em painel com efeito fixo. O item 4.4 apresenta o resultado da regressão em pooled para os retornos anormais e também o teste de Vuong (1989) com o objetivo de comparar os modelos estudados.

Petersen (2009) em seu estudo compara e avalia os resultados dos erros padrão dos diferentes métodos estatísticos utilizados nos trabalhos de finanças corporativas e precificação de ativos. Neste artigo procurou-se realizar diferentes testes estatísticos (pooled, Fama-Macbeth e painel) para a mesma base de dados com o objetivo de aumentar a robustez dos resultados encontrados.

Nos testes realizados, são comparados os coeficientes e as respectivas significâncias assim como seu poder explicativo $\left(R^{2}\right)$. Vale ressaltar que não existe uma regra pré-definida para julgamento dos coeficientes e do poder explicativo das variáveis estudadas. Os valores identificados nos testes serão comparados entre os modelos estudados neste trabalho, a partir de dados do mercado brasileiro e dos encontrados nos testes realizados no mercado americano. 


\subsection{Resultados para amostras em pooled}

Os resultados das regressões para amostras em pooled são apresentados na Tabela 1. Todas as regressões foram realizadas considerando-se a matriz de variância robusta à heterocedasticidade. O modelo (6) apresenta significância de 1\% para as variáveis independentes com exceção da variável variação da rentabilidade, que apresenta significância em $10 \%$. Os sinais dos coeficientes das variáveis são todos condizentes com a previsão do modelo. No modelo (7) a variável $\Delta \hat{q}_{i t}$ não é significante. As demais variáveis apresentam significância entre 1 e 10\%. Para esse modelo, os sinais dos coeficientes que possuem significância correspondem com o previsto pela teoria. O $R^{2}$ ajustado para o modelo (6) é de $33.20 \%$ e para o modelo (7) é de $34.40 \%$.

O coeficiente do lucro líquido $\left(x_{i t}\right)$ é $0.50(t=8.81)$ para o modelo $(6)$ e 0.48 $(t=8.71)$ para o modelo (7), sendo ambos significantes em $1 \%$. Mesmo os coeficientes não tendo apresentado valores tão próximos a 1 , conforme previsto na teoria, eles são significantes e positivos. A variação da rentabilidade $\Delta \hat{q}_{i t}$ possui coeficiente $0.07(t=1.89)$, significante em $10 \%$ no modelo (6). No modelo (7) a variável $\Delta \hat{q}_{i t}$, que representa a faixa de baixa rentabilidade, não é significante. $\mathrm{O}$ coeficiente para $M \Delta \hat{q}_{i t}$, que representa a faixa de rentabilidade média, é de 1.56 $(t=1.94)$ com significância em $10 \%$. O coeficiente para $H \Delta \hat{q}_{i t}$, que representa a faixa de alta rentabilidade, é $0.14(t=2.04)$ com significância em 5\%. A maior significância e a amplitude dos coeficientes das variáveis de média e alta rentabilidade, em relação ao coeficiente de baixa rentabilidade, indicam que a variação da rentabilidade impacta o retorno, conforme proposto pela teoria e também identificado no mercado norte americano.

O capital investido $\Delta \hat{b}_{i t}$ possui o coeficiente $0.21(t=3.87)$ e é significante em $1 \%$ tanto para o modelo (6) quanto para o modelo (7). O sinal do coeficiente positivo sugere que, na média, o capital investido leva à criação de um valor líquido positivo. $\mathrm{O}$ valor 0.21 é inferior ao previsto (próximo de 1), no entanto significativo e positivo. No mercado norte-americano, o valor encontrado também não foi tão próximo a 1.

A variação da oportunidade de crescimento $\Delta \hat{g}_{i t}$ possui o coeficiente $0.25(t=$ 8.17 ) e significante em $1 \%$ no modelo (6). No modelo (7) o coeficiente para a variável $\Delta \hat{g}_{i t}$, que representa a faixa de baixa rentabilidade, é de $0.20(t=5.00)$ significante em $1 \%$. O valor dos coeficientes para $M \Delta \hat{g}_{i t}$, faixa que representa a rentabilidade média, aumenta para $0.26(t=2.76)$, significante em $1 \%$. E para $H \Delta \hat{g}_{i t}$, que representa a faixa de alta rentabilidade, é $0.30(t=7.80)$ significante em $1 \%$. Os resultados são condizentes com a previsão teórica de que o impacto da variação da oportunidade de crescimento no retorno é maior para firmas com maior rentabilidade.

O coeficiente da variação da taxa de desconto é significante em $1 \%$ para ambos os modelos e é negativo conforme previsto, entretanto é muito pequeno, representativo somente na terceira casa decimal. 
Tabela 2

Resultado das regressões das amostras em pooled

\begin{tabular}{|c|c|c|c|c|c|c|c|}
\hline \multirow[t]{2}{*}{ Variável } & \multirow{2}{*}{$\begin{array}{c}\text { Previsão } \\
\text { valor/sinal }\end{array}$} & \multicolumn{2}{|c|}{ Modelo (6) } & \multicolumn{2}{|c|}{ Modelo (7) } & \multicolumn{2}{|c|}{ Modelo (8) } \\
\hline & & coef. & $t$ stat & coef. & $t$ stat & coef. & $t$ stat \\
\hline \multirow[t]{11}{*}{ Int. } & $+/-$ & -0.01 & $(-0.86)$ & $-0.02 *$ & $(-1.76)$ & $0.08 *$ & $(5.60)$ \\
\hline & +1 & $0.50 * * *$ & $(8.81)$ & $0.48 * * *$ & $(8.71)$ & $0.29 * * *$ & $(4.26)$ \\
\hline & + & & & & & $0.09 *$ & (1.88) \\
\hline & + & $0.07 *$ & (1.89) & -0.01 & $(-0.12)$ & & \\
\hline & + & & & $1.56^{*}$ & $(1.94)$ & & \\
\hline & + & & & $0.14 * *$ & $(2.04)$ & & \\
\hline & +1 & $0.21 * * *$ & $(3.87)$ & $0.21 * * *$ & $(3.87)$ & & \\
\hline & + & $0.25 * * *$ & $(8.17)$ & $0.20 * * *$ & $(5.00)$ & & \\
\hline & + & & & $0.26 * * *$ & $(2.76)$ & & \\
\hline & + & & & $0.30 * * *$ & $(7.80)$ & & \\
\hline & - & $-0.00 * * *$ & $(-3.76)$ & $-0,00 * * *$ & $(-3.56)$ & & \\
\hline $\mathrm{F}$ & & $55.42 * * *$ & & $30.40 * * *$ & & & $16.27 * * *$ \\
\hline $\mathrm{R}^{2}$ ajust. & & 33.20 & & 34.40 & & & 6.92 \\
\hline \multicolumn{8}{|c|}{$\begin{array}{l}\text { Nota: } x_{i t}=X_{i t} / V_{i t-1} \text { : é o lucro da firma } i \text { no ano } t \text { dividido pelo valor de mercado da firma } i \text { no ano } \\
t-1 \text {. }\end{array}$} \\
\hline \multicolumn{8}{|c|}{$\begin{array}{l}\Delta \hat{q}_{i t}=\left(q_{i t}-q_{i t-1}\right) B_{i t-1} / V_{i t-1} \text { : é a variação na rentabilidade da firma } i \text { no ano } t \text {, ajustado pela } \\
\text { razão patrimônio líquido e valor de mercado em } t-1 \text {, sendo a rentabilidade } q_{i t}=X_{i t} / B_{i t-1} \text { definida } \\
\text { como o retorno sobre o patrimônio líquido. }\end{array}$} \\
\hline \multicolumn{8}{|c|}{$\begin{array}{l}\Delta \hat{b}_{i t}=\left[\left(B_{i t}-B_{i t-1}\right) / B_{i t-1}\right]\left(1-B_{i t-1} / V_{i t-1}\right) \text { : é o patrimônio líquido (capital investido) ou } \\
\text { mudança proporcional no patrimônio líquido da firma } i \text { no ano } t \text {, ajustado por um menos o book-to-market } \\
\text { em } t-1 \text {. }\end{array}$} \\
\hline \multicolumn{8}{|c|}{$\begin{array}{l}\Delta \hat{g}_{i t}=\left(g_{i t}-g_{i t-1}\right) B_{i t-1} / V_{i t-1} \text { : é a variação da oportunidade de crescimento da firma } i \text { no } \\
\text { ano } t \text {, ajustado pelo book-to-market em } t-1 \text {. Neste estudo } g_{i t}=V_{i t} / B_{i t} \text {, ou seja, foi utilizado o } \\
\text { market-to-book ou price-to-book como proxy para crescimento. }\end{array}$} \\
\hline \multicolumn{8}{|c|}{$\begin{array}{l}\Delta \hat{r}_{i t}=\left(r_{i t}-r_{i t-1}\right) B_{i t-1} / V_{i t-1} \text { : é a variação da taxa de desconto no ano } t \text { ajustado pelo book- } \\
\text { to-market em } t-1 \text {. }\end{array}$} \\
\hline \multicolumn{8}{|c|}{$\begin{array}{l}M \text { e } H \text { : são variáveis dummy para as diferentes rentabilidades, média (um terço médio) e alta (terça parte } \\
\text { superior) da rentabilidade das amostras. }\end{array}$} \\
\hline \multicolumn{8}{|c|}{$F:$ Valor da estatística $F$. } \\
\hline \multicolumn{8}{|c|}{$R^{2}$ ajust.: Coeficiente da regressão. } \\
\hline
\end{tabular}

O modelo (8) baseado em lucro apresenta $\mathrm{R}^{2}$ ajustado de $6.92 \%$. A variável lucro líquido $x_{i t}$ apresenta coeficiente $0.29(t=4.26)$ significante em $1 \%$, e a variação do lucro líquido $\Delta x_{i t}$ apresenta coeficiente $0.09(\mathrm{t}=1.88)$ significante em $10 \%$.

Com o objetivo de avaliar os três modelos, o teste comparativo de Vuong (1989) foi aplicado. Esse teste leva em consideração dois modelos, sendo $\hat{P}_{1}=$ $\left(y_{i} \mid x_{i}\right)$ o valor da probabilidade de observar $y$ no primeiro modelo e $\hat{P}_{2}=\left(y_{i} \mid\right.$ $x_{i}$ ) o valor da probabilidade para o segundo modelo. 
O teste de Vuong (1989) verifica a hipótese $H_{0}: E(m)=0$ onde:

$$
\begin{gathered}
m_{i}=\ln \left[\frac{\hat{P}_{1}=\left(y_{i} \mid x_{i}\right)}{\hat{P}_{2}=\left(y_{i} \mid x_{i}\right)}\right] \\
Z=\frac{\sqrt{N} \bar{m}}{s_{m}}
\end{gathered}
$$

sendo $\bar{m}$ a média, $s_{m}$ o desvio-padrão de $m_{i}$ e $N$ número de amostras. Se $Z>$ 1.96, o primeiro modelo é mais significante. Se $Z<-1.96$, o segundo modelo é mais significante. Quando $-1.96<Z<1.96$, o teste é inclusivo.

Nos testes realizados, foram encontrados os seguintes resultados:

- Comparação entre o modelo (6) e o modelo (7): $Z=-1.37$.

- Comparação entre o modelo (6) e o modelo (8): $Z=6.92$.

- Comparação entre o modelo (7) e o modelo (8): $Z=7.80$.

Os testes de Vuong são inconclusivos quando comparados os modelos (6) e (7). Porém o modelo (8) apresenta menor poder explicativo que os modelos (6) e (7) desenvolvidos por Zhang \& Chen (2007).

\subsection{Resultados para amostras anuais e painel Fama-MacBeth}

Nesta seção, são apresentados os resultados dos retornos e os coeficientes de seus estimadores para as amostras classificadas anualmente e também são apresentadas as médias dos coeficientes baseadas nas amostras anuais calculadas pelo método Fama-MacBeth. ${ }^{6}$ Esses resultados são apresentados nas Tabelas 2, 3 e 4 respectivamente para os modelos (6), (7) e (8).

\footnotetext{
${ }^{6}$ Técnica estatística de dados em painel desenvolvida por Fama \& Macbeth (1973) tendo sido utilizado para estimar parâmetros de modelos de precificação de ativos tais como Capital Asset Pricing Model (CAPM). Os parâmetros desses testes são estimados em duas etapas: Na primeira, é realizada a regressão de cada ativo contra os fatores de risco propostos para determinar o beta do ativo. $\mathrm{Na}$ segunda, é realizada a regressão com todos os retornos de ativos em um determinado período de tempo contra os betas estimados para determinar o prêmio de risco para cada fator.
} 
Tabela 3
Modelo (6) - Resultado das regressões lineares anuais das amostras e painel Fama-MacBeth

\begin{tabular}{|c|c|c|c|c|c|c|c|c|c|}
\hline Ano & Obs & Int. & $x_{i t}$ & $\Delta \hat{q_{i t}}$ & $\widehat{\Delta \Delta \hat{b_{i t}}}$ & $\Delta \hat{g_{i t}}$ & $\Delta \hat{r_{i t}}$ & $F$ & $R^{2}(\%)$ \\
\hline 1997 & 103 & $-0.15 * *$ & $0.46^{* * * *}$ & -0.09 & 0.03 & $0.42^{* * * *}$ & 0.00 & $8.09^{* * *}$ & 37.93 \\
\hline 1998 & 110 & -0.06 & $0.38^{* * * *}$ & 0.17 & -0.16 & $0.75^{* * * *}$ & 0.00 & $12.18^{* * * *}$ & 34.69 \\
\hline 1999 & 110 & $0.27^{* * * *}$ & $0.22^{* *}$ & 0.02 & 0.05 & $0.12^{*}$ & 0.00 & $6.65^{* * * *}$ & 25.87 \\
\hline 2000 & 135 & -0.04 & $0.48^{* * * *}$ & 0.14 & 0.13 & $0.43^{* * * *}$ & -0.01 & $6.63^{* * * *}$ & 29.40 \\
\hline 2001 & 127 & -0.09 & $0.46^{* * * *}$ & -0.01 & $0.34 * *$ & 0.11 & 0.01 & $2.84^{* *}$ & 15.34 \\
\hline 2002 & 144 & $-0.13 * *$ & $0.81^{* * * *}$ & 0.13 & $0.92 * * *$ & $0.13^{* * *}$ & 0.01 & $8.40^{* * * *}$ & 37.66 \\
\hline 2003 & 135 & $0.29 * * *$ & $0.60^{* * * *}$ & -0.03 & $0.43^{* * *}$ & $0.41^{* * * *}$ & 0.00 & $22.88^{* * * *}$ & 60.72 \\
\hline 2004 & 143 & 0.08 & $0.92^{* * * *}$ & 0.02 & $0.36^{* * *}$ & $0.20^{*}$ & 0.03 & $8.21^{* * * *}$ & 36.94 \\
\hline 2005 & 152 & $0.13^{*}$ & 0.41 & 0.39 & 0.05 & $0.31^{* * *}$ & 0.10 & $25.16^{* * * *}$ & 45.87 \\
\hline 2006 & 145 & $0.21 * *$ & -0.10 & $0.43 * * *$ & 0.01 & $0.21^{* * * *}$ & -0.01 & $4.58^{* * * *}$ & 25.97 \\
\hline 2007 & 175 & 0.00 & $0.71 * * *$ & -0.02 & $0.28^{* * * *}$ & $0.22^{* * * *}$ & 0.02 & $9.96^{* * * *}$ & 38.47 \\
\hline 2008 & 199 & $-0.52 * * *$ & $1.93^{* * * *}$ & $-0.45 * * *$ & $0.29^{*}$ & $0.44 * *$ & 0.02 & $12.4^{* * * *}$ & 40.08 \\
\hline Fama-MacBeth & 1678 & 0.00 & $0.61^{* * * *}$ & 0.06 & $0.23^{* * *}$ & $0.31^{* * * *}$ & 0.01 & $23.23 * * *$ & 35.74 \\
\hline t stat & & $(-0.04)$ & $(4.23)$ & $(0.87)$ & $(2.82)$ & $(5.79)$ & (1.48) & & \\
\hline Sinal previsto & & $+/-$ & + & + & + & + & & & \\
\hline
\end{tabular}

$\Delta \hat{q}_{i t}=\left(q_{i t}-q_{i t-1}\right) B_{i t-1} / V_{i t-1}$ : é a variação na rentabilidade da firma $i$ no ano $t$, ajustado pela razão patrimônio líquido e $\Delta \hat{b}_{i t}=\left[\left(B_{i t}-B_{i t}-1\right) / B_{i t-1}\right]\left(1-B_{i t}-1 / V_{i t}-1\right): \boldsymbol{c}_{i t-1}$ defila

$\Delta \hat{b}_{i t}=\left[\left(B_{i t}-B_{i t-1}\right) / B_{i t-1}\right]\left(1-B_{i t-1} / V_{i t-1}\right)$ : é o patrimônio líquido (capital investido) ou mudança proporcional no

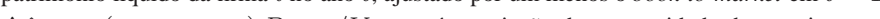

$\Delta \hat{g}_{i t}=\left(g_{i t}-g_{i t-1}\right) B_{i t-1} / V_{i t-1}$. e a variação da oportunidade de crescimento da firma $i$ no ano $t$, ajustado pelo book-to-

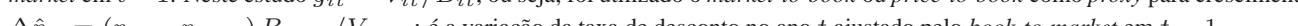
$\Delta \hat{r}_{i t}=\left(r_{i t}-r_{i t-1}\right) B_{i t-1} / V_{i t-1}$ : é a variação da taxa de desconto no ano $t$ ajustado pelo book-to-market em $t-1$,

$M$ e $H$ : são variáveis dummy para as diferentes rentabilidades, média (um terço médio) e alta (terça parte superior) da rentabilidade das amostras.

$F$ : Valor da estatística $F$

\& $\quad R^{2}$ ajust.: Coeficiente da regressão.

*** indica significância em 1\%,** indica significância em 5\% e * indica significância em 10\%. 
Tabela 5

Modelo (8) - Resultado das regressões lineares (benchmarck) anuais das amostras e painel Fama-MacBeth

\begin{tabular}{l|c|c|c|c|c|c}
\hline Ano & Obs. & Int. & $x_{i t}$ & $\Delta x_{i t}$ & $F$ & $R^{2}(\%)$ \\
\hline 1997 & 103 & $-0.10^{* *}$ & $0.35^{* * *}$ & 0.01 & $12.99^{* * *}$ & 14.68 \\
\hline 1998 & 110 & $-0.21^{* * *}$ & $0.27^{*}$ & -0.03 & 1.72 & 6.75 \\
\hline 1999 & 110 & $0.53^{* * *}$ & 0.14 & -0.02 & 0.49 & 3.32 \\
\hline 2000 & 135 & 0.06 & 0.15 & 0.15 & $3.3 * *$ & 8.30 \\
\hline 2001 & 127 & -0.03 & $0.19^{*}$ & -0.04 & 1.78 & 4.08 \\
\hline 2002 & 144 & 0.00 & $0.44^{* * *}$ & -0.01 & $12.82^{* * *}$ & 18.76 \\
\hline 2003 & 135 & $0.51^{* * *}$ & $0.23^{* *}$ & $0.19^{* *}$ & $9.32^{* * *}$ & 19.70 \\
\hline 2004 & 143 & $0.26^{* * *}$ & $0.61^{* * *}$ & 0.19 & $8.66^{* * *}$ & 21.98 \\
\hline 2005 & 152 & $0.20^{* * *}$ & $0.21^{*}$ & $0.72^{* * *}$ & $11.64^{* * *}$ & 34.61 \\
\hline 2006 & 145 & $0.35^{* * *}$ & $-0.26^{*}$ & $0.34^{*}$ & 1.76 & 2.73 \\
\hline 2007 & 175 & $0.15^{* * *}$ & 0.33 & 0.10 & 0.9 & 2.34 \\
\hline 2008 & 199 & $-0.68^{* * *}$ & $2.63^{* * *}$ & $-1.35^{* * *}$ & $23.56^{* * *}$ & 27.86 \\
\hline Fama-MacBeth & 1678 & 0.09 & $0.44^{*}$ & 0.02 & $12.33^{* * *}$ & 13.76 \\
\hline$t$ stat & & $(0.89)$ & $(2.11)$ & $(0.15)$ & & \\
\hline Sinal previsto & & $+/-$ & + & + & & \\
\hline Nota: & & & + & & \\
\hline
\end{tabular}

Nota: $x_{i t}=X_{i t} / V_{i t-1}$ : é o lucro da firma $i$ no ano $t$ dividido pelo valor de mercado da firma $i$ no ano $t-1$.

$\Delta \hat{q}_{i t}=\left(q_{i t}-q_{i t-1}\right) B_{i t-1} / V_{i t-1}$ : é a variação na rentabilidade da firma $i$ no ano $t$, ajustado pela razão patrimônio líquido e valor de mercado em $t-1$, sendo a rentabilidade $q_{i t}=X_{i t} / B_{i t-1}$ definida como o retorno sobre o patrimônio líquido.

$\Delta \hat{b}_{i t}=\left[\left(B_{i t}-B_{i t-1}\right) / B_{i t-1}\right]\left(1-B_{i t-1} / V_{i t-1}\right)$ : é o patrimônio líquido (capital investido) ou mudança proporcional no patrimônio líquido da firma $i$ no ano $t$, ajustado por um menos o book-to-market em $t-1$.

$\Delta \hat{g}_{i t}=\left(g_{i t}-g_{i t-1}\right) B_{i t-1} / V_{i t-1}$ : é a variação da oportunidade de crescimento da firma $i$ no ano $t$, ajustado pelo book-to-market em $t-1$. Neste estudo $g_{i t}=V_{i t} / B_{i t}$, ou seja, foi utilizado o market-to-book ou price-to-book como proxy para crescimento.

$\Delta \hat{r}_{i t}=\left(r_{i t}-r_{i t-1}\right) B_{i t-1} / V_{i t-1}$ : é a variação da taxa de desconto no ano $t$ ajustado pelo book-to-market em $t-1$.

$M$ e $H$ : são variáveis dummy para as diferentes rentabilidades, média (um terço médio) e alta (terça parte superior) da rentabilidade das amostras.

$F$ : Valor da estatística $F$.

$R^{2}$ ajust.: Coeficiente da regressão.

*** indica significância em 1\%, ** indica significância em 5\% e * indica significância em 10\%.

O coeficiente médio obtido pelo método Fama-MacBeth para o lucro líquido é $0.61(t=4.23)$ para o modelo $(6)$ e $0.61(t=4.09)$ para o modelo (7). Além de os coeficientes serem iguais para os modelos, eles também são significantes em $1 \%$. Quanto à análise anual, o lucro líquido possui 9 coeficientes significantes em 1\% e 1 coeficiente significante em 5\% no modelo (6) entre os 12 anos. O modelo (7) possui 9 coeficientes significantes em $1 \%$ e 1 coeficiente significante em 10\%. Em ambos os modelos, os coeficientes significativos para os dados anuais apresentam sinal positivo e conforme a previsão teórica. Os dados encontrados para o lucro líquido são condizentes com os encontrados no trabalho de Zhang \& Chen (2007).

O coeficiente médio obtido pelo método Fama-MacBeth para variação da rentabilidade ( $\Delta \hat{q}_{i t}$ ) no modelo (6) não é significativo. Para o modelo (7), o coeficiente para a variação da rentabilidade $\Delta \hat{q}_{i t}$ (baixa rentabilidade) é $0.10(t=2.43)$ e significante em $5 \%$. $M \Delta \hat{q_{i t}}$ (rentabilidade intermediária) possui coeficiente de $1.30(t=2.35)$, assim como nos dados em pooled, trata-se do maior coeficiente 


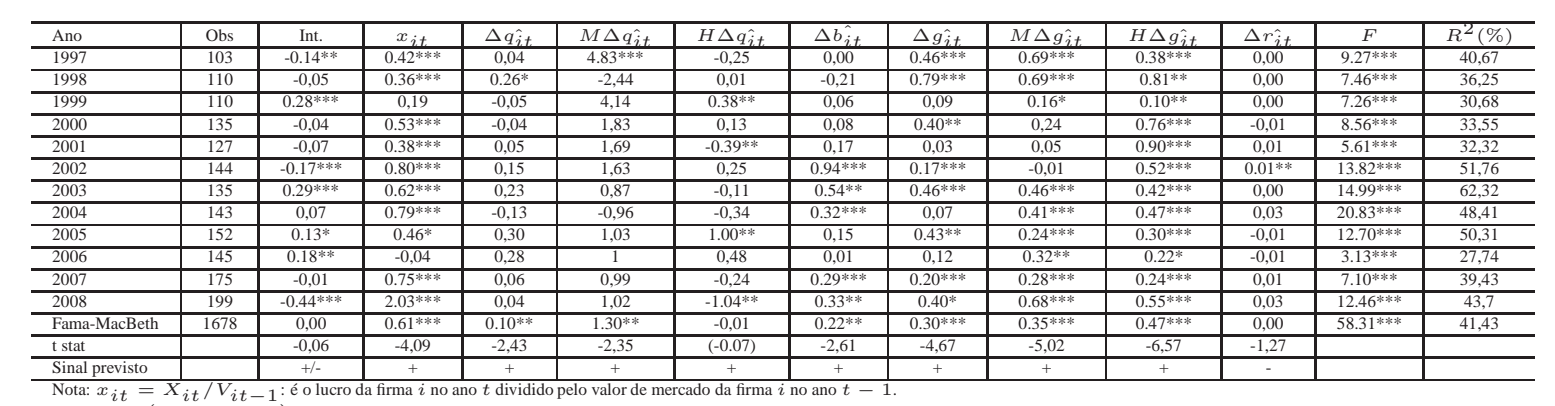

Nota: $x_{i t}=x_{i t} / V_{i t-1}: \dot{e}$ olucro da firma $i$ no ano $t$ dividido pelo valor de mercado da firma $i$ no ano $t-1$.
$\Delta \hat{q}_{i t}=\left(q_{i t}-q_{i t}\right.$
$B_{i t}$ $\Delta \hat{q}_{i t}=\left(q_{i t}-q_{i t-1}\right) B_{i t-1} / V_{i t-1}$ : éa variação na rentabilidade da firma $i$ no ano $t$, ajustado pela razão patrimônio líquido e valor de mercado em $t-1$, sendo a rentabilidade
$q_{i t}=X_{i} / B_{i t}-$ definida como o retorno sobre o patrimônio líquido $q_{i t}=X_{i t} / B_{i t}-1$
$\Delta \hat{b}_{i t}=\left[\left(B_{i t}-B_{i t-1}\right) / B_{i t}-1\right]\left(1-B B_{i t}-1 / V_{i t}-1\right)$

$\Delta \hat{b}_{i t}=\left[\left(B_{i t}-B_{i t-1}\right) / B_{i t-1}\right]\left(1-B_{i t-1} / V_{i t-1}\right): e ́$ p patrimônio líquido (capital investido) ou mudança proporcional no patrimônio líquido da firma $i$ no ano $t$, ajustado por
um menoso o book-to-market em $t-1$. $\Delta \hat{g}_{i t}=\left(g_{i t}-g_{i t}-1\right) B_{i}$

$B_{i t-1} / V_{i t-1}$ : é a variaçăo da oportunidade de crescimento da firma $i$ no ano $t$, ajustado pelo book-to-market em $t-1$. Neste estudo $g_{i t}=V_{i t} / B_{i t}$, ou

$\Delta \hat{r}_{i t}=\left(r_{i t}-r_{i t-1}\right) B_{i t-1} / V_{i t-1}$ : é a variação da taxa de desconto no ano $t$ ajustado pelo book-to-market em $t-1$.

$M \mathrm{e} H$ : são variáveis dummy para as diferentes rentabilidades, média (um terço médio) e alta (terça parte superior) da rentabilidade das amostras

$R^{2}$ a just.: Coeficiente da regressão.
$* * *$ indica significância em $1 \%$, $*$ indica significância em $5 \%$ e* indica significância em $10 \%$. 
entre os três níveis de rentabilidade. O coeficiente $H \Delta \hat{q_{i t}}$ (alta rentabilidade) não é significante. Em Zhang \& Chen (2007) os coeficientes médios (Fama-MacBeth) para a variação de rentabilidade são significativos em $1 \%$ em ambos os modelos, e o coeficiente é tão maior quanto o nível de rentabilidade. Os coeficientes para a variação de rentabilidade analisados anualmente no modelo (6) apresentam significância somente em apenas 2 anos de um total de 12. O modelo (7) apresenta somente um ano com significância para a variação da rentabilidade $\Delta \hat{q_{i t}}$ (baixa rentabilidade). A rentabilidade $M \Delta \hat{q_{i t}}$ (rentabilidade intermediária) possui também somente um ano significante. $\mathrm{O}$ coeficiente da rentabilidade $H \Delta \hat{q_{i t}}$ (alta rentabilidade) é significante em quatro anos, porém, em dois anos, possui sinal negativo, diferente do esperado. Os dados anuais encontrados em Zhang \& Chen (2007) foram mais significativos dos que encontrados neste artigo. Entretanto vale ressaltar que também foi identificado um menor número de coeficientes significantes para a rentabilidade $\Delta \hat{q_{i t}}$ (baixa rentabilidade) no modelo (7), 11 em 19 anos, em comparação com a quantidade de coeficientes significantes para $M \Delta \hat{q_{i t}}$ e $H \Delta \hat{q_{i t}}$, respectivamente 15 e 17 anos.

O coeficiente médio para o capital investido $\Delta \hat{b_{i t}}$ é $0.23(t=2.82)$ para o modelo (6) e $0.22(t=2.61)$ para o modelo $(7)$, sendo ambos significantes em $5 \%$. Os valores dos coeficientes médios são próximos dos encontrados para os dados em pooled, que são $0.21(t=3.87)$ para os modelos $(6)$ e (7). Em relação aos dados anuais, ambos os modelos possuem 5 anos significantes em 12, e todos os sinais são positivos conforme previsto pela teoria. Zhang \& Chen (2007) obtiveram resultados semelhantes, inclusive coeficientes inferiores ao valor previsto (coeficiente com valor igual a 1).

O modelo (6) possui coeficientes médios de $0.31(t=5.79)$, significante em $1 \%$ para a variação da oportunidade de crescimento. Para o modelo (7), o coeficiente médio da oportunidade de crescimento $\Delta \hat{g_{i t}}$ para baixa rentabilidade é $0.30(t=4.67)$ significante em $1 \%$. Os valores dos coeficientes médios da variação de oportunidade de crescimento $M \Delta \hat{g_{i t}}$ (rentabilidade intermediária) é $0.35(t=5.02)$, significante em $1 \%$. A oportunidade de crescimento $H \Delta \hat{g_{i t}}$ (alta rentabilidade) é $0.47(t=6.57)$. Assim como na regressão realizada com amostra em pooled, os coeficientes são crescentes de acordo com o aumento da rentabilidade. Os dados anuais para a variação da oportunidade de crescimento são significantes em 11 dos 12 anos para o modelo (6), e todos os sinais são positivos conforme esperado. Para o modelo (7), $\Delta \hat{g_{i t}}, M \Delta \hat{g_{i t}}$ e $H \Delta \hat{g_{i t}}$ possuem respectivamente 8,9 e 12 anos significantes, e todos os sinais são positivos, de acordo com o previsto. Zhang \& Chen (2007) não encontraram coeficiente significante para $M \Delta \hat{g_{i t}}$ (variação da oportunidade de crescimento para rentabilidade intermediária) no modelo (7). 
A variação da taxa de desconto não apresentou coeficientes médios significativos para nenhum dos modelos. Anualmente, a taxa foi significante somente para um ano no modelo (7). Nos estudos para o mercado norte-americano, os coeficientes médios foram significativos em 5\% para ambos os modelos. Para os dados anuais, o modelo (6) apresentou 11 anos significativos, e o modelo (7) apresentou 10 anos dos 19 estudados. Em todos os casos significativos os coeficientes apresentaram sinal negativo conforme previsão do modelo.

O modelo (6) apresentou uma variação do $\mathrm{R}^{2}$ ajustado de $15.34 \%$ (2001) a $60.72 \%$ (2003), com um valor médio de $35.74 \%$. O modelo (7) apresentou uma variação do $\mathrm{R}^{2}$ ajustado de $27.74 \%$ (2005) a $62.32 \%$ (2003), com um valor médio de $41.70 \%$.

O modelo (8), baseado em lucros, apresentou coeficiente médio de 0.44 $(t=2.11)$, significativo em $10 \%$ para o lucro liquido $x_{i t}$. A variável variação do lucro líquido $\Delta x_{i t}$ não apresentou coeficiente médio significante. Anualmente, a variável lucro líquido apresentou 9 anos significantes em 12. Já a variável variação do lucro líquido $\Delta x_{i t}$ apresentou somente 4 anos significantes. Os valores anuais dos $\mathrm{R}^{2}$ ajustados variaram de $2.34 \%$ (2007) a $34.61 \%$ (2005), com valor médio de $13.76 \%$.

Comparativamente, o modelo (6) e o modelo (7) obtiveram um maior poder explicativo que o apresentado pelo modelo (8) baseado em lucros. Isso pode ser observado tanto na significância dos coeficientes quanto nos $\mathrm{R}^{2}$ médios e anuais.

\subsection{Dados em painel}

Além das técnicas de regressão em pooled e Fama-Macbeth, com o intuito de aumentar a robustez dos resultados encontrados, as amostras foram aplicadas a técnica de dados em painel com efeito fixo. ${ }^{7}$ Os resultados são apresentados na Tabela 5 .

\footnotetext{
${ }^{7}$ Realizamos o teste de Hausman, o qual avalia se os coeficientes estimados por painel com efeito fixo e efeito aleatório são sistematicamente diferentes. Com base nos seus resultados, o modelo de painel com efeitos fixos mostrou-se adequado e por isso utilizado nesse trabalho.
} 
Tabela 6

Resultado das regressões das amostras em painel efeito fixo

\begin{tabular}{|c|c|c|c|c|c|c|c|}
\hline \multirow[t]{2}{*}{ Variável } & \multirow{2}{*}{$\begin{array}{c}\text { Previsão } \\
\text { Valor/ Sinal }\end{array}$} & \multicolumn{2}{|c|}{ Modelo (6) } & \multicolumn{2}{|c|}{ Modelo (7) } & \multicolumn{2}{|c|}{ Modelo (8) } \\
\hline & & Coef. & $t$ stat & Coef. & $t$ stat & Coef. & $t$ stat \\
\hline \multirow[t]{11}{*}{ Intercep. } & $+/-$ & -0.01 & $(-0.78)$ & $-0.31^{*}$ & $(-1.93)$ & $0.08^{* * * *}$ & $(5.92)$ \\
\hline & 1 & $0.49 * * *$ & $(7.13)$ & $0.45^{* * * *}$ & (7.11) & $0.27 * * *$ & (3.02) \\
\hline & + & & & & & 0.09 & (1.42) \\
\hline & + & 0.03 & $(0.64)$ & -0.09 & $(-1.64)$ & & \\
\hline & + & & & 1.36 & (1.48) & & \\
\hline & + & & & $0.17^{*}$ & $(1.93)$ & & \\
\hline & 1 & $0.20 * * *$ & $(2.91)$ & $0.19^{* * * *}$ & $(2.92)$ & & \\
\hline & + & $0.25 * * *$ & $(7.78)$ & $0.21^{* * * *}$ & $(4.40)$ & & \\
\hline & + & & & $0.23^{* * * *}$ & $(2.59)$ & & \\
\hline & + & & & $0.30^{* * *}$ & $(6.92)$ & & \\
\hline & - & $-0.00 * * *$ & $(-3.41)$ & $-0,00$ **** & $(-3.03)$ & & \\
\hline $\mathrm{F}$ & & $40.92 * * *$ & & $22.32^{* * * *}$ & & & $14.60 * * *$ \\
\hline$R^{2}$ within (\%) & & 32.74 & & 34.04 & & & 5.20 \\
\hline$R^{2}$ between $(\%)$ & & 31.03 & & 37.17 & & & 3.33 \\
\hline$R^{2}$ overall $(\%)$ & & 33.00 & & 33.82 & & & 6.92 \\
\hline \multicolumn{8}{|c|}{$\begin{array}{l}\text { Nota: } x_{i t}=X_{i, t} / V_{i t-1} \text { : é o lucro da firma } i \text { no ano } t \text { dividido pelo valor de mercado da firma } i \text { no ano } \\
t-1 \text {. } \\
\Delta \hat{q}_{i t}=\left(q_{i t}-q_{i t-1} B_{i t-1} / V_{i t-1} \text { : é a variação na rentabilidade da firma } i \text { no ano } t \text {, ajustado pela }\right. \\
\text { razão patrimônio líquido e valor de mercado em } t-1 \text {, sendo a rentabilidade definida como o retorno sobre o } \\
\text { patrimônio líquido. }\end{array}$} \\
\hline \multicolumn{8}{|c|}{$\begin{array}{l}\Delta \hat{b}_{i t}=\left[\left(B_{i t}-B_{i t-1}\right) / B_{i t-1}\right]\left(1-B_{i t-1} / V_{i t-1}\right) \text { : é o patrimônio líquido (capital investido) ou } \\
\text { mudança proporcional no patrimônio líquido da firma } i \text { no ano } t \text {, ajustado por um menos o book-to-market em } \\
t-1 \text {. }\end{array}$} \\
\hline \multicolumn{8}{|c|}{$\begin{array}{l}\Delta \hat{g}_{i t}=\left(g_{i t}-g_{i t-1}\right) B_{i t-1} / V_{i t-1} \text { é a variação da oportunidade de crescimento da firma } i \text { no ano } t \text {, } \\
\text { ajustado pelo book-to-market em } t-1 \text {. Neste estudo } g_{i t}=V_{i t} / B_{i t} \text {, ou seja, foi utilizado o market-to-book } \\
\text { ou price-to-book como proxy para crescimento. }\end{array}$} \\
\hline \multicolumn{8}{|c|}{$\begin{array}{l}\Delta \hat{r}_{i t}=\left(r_{i t}-r_{i t-1}\right) B_{i t-1} / V_{i t-1} \text { é a variação da taxa de desconto no ano } t \text { ajustado pelo book-to- } \\
\text { market em } t-1 \text {. }\end{array}$} \\
\hline \multicolumn{8}{|c|}{$\begin{array}{l}M \text { e } H \text { : são variáveis dummy para as diferentes rentabilidades, média (um terço médio) e alta (terça parte } \\
\text { superior) da rentabilidade das amostras. } \\
F \text { : Valor da estatística } F \text {. }\end{array}$} \\
\hline
\end{tabular}

Os resultados da aplicação da técnica dados em painel ao modelo (6) apresentaram coeficientes significantes e com sinal conforme previsto pelo modelo teórico, com exceção da variação da rentabilidade, que não apresentou resultado significante. A magnitude dos sinais encontrados é próxima da encontrada nas regressões em pooled da Tabela 1. O modelo (7) também obteve coeficientes significantes e sinal conforme previsto pelo modelo, com exceção dos coeficientes $\Delta \hat{q}_{i t}$ e $M \Delta \hat{q}_{i t}$, que não apresentaram significância. A magnitude dos coeficientes também foi próxima à apresentada pela regressão em pooled. O modelo (8) apresentou significância e sinal conforme previsto pelo modelo. $\mathrm{O}$ coeficiente do lucro apresentou valores próximos aos encontrados no teste em pooled, no entanto a variação do lucro não apresentou significância.

Os valores dos $R^{2}$ ajustados para os modelos (6), (7) e (8) também são muito próximos aos resultados encontrados quando aplicada a técnica de regressão em pooled.

Os resultados apresentados pelos dados em painel nesse item reforçam os resultados previamente encontrados nos outros testes de regressão realizados neste artigo. 


\subsection{Resultados empíricos baseados em regressões utilizando o retorno anor- mal}

Partindo-se do princípio que as análises empíricas não são suficientes para explicar completamente o retorno das ações, pode-se argumentar que, se os fundamentos contábeis refletem a performance financeira de determinadas firmas, eles também poderiam explicar o risco idiossincrático específico de cada uma delas. Essa suposição advém de que variações nos dados contábeis estão relacionadas ao risco total das firmas, então, essas variações contêm tanto as variações sistemáticas quanto as idiossincráticas.

De acordo com a teoria Asset Pricing Model (CAPM - Capital Asset Pricing Model), os investidores mantêm portfólios diversificados, e a expectativa de retorno de uma ação é determinada pelo risco sistemático, em que o retorno anormal é atribuído ao risco idiossincrático. Zhang \& Chen (2007), em seu trabalho, levantam o questionamento de que os fundamentos contáveis também poderiam explicar o retorno anormal. Para avaliar esse questionamento foram desenvolvidas as equações (6'), (7') e (8') a partir das equações (6), (7) e (8).

$$
\begin{aligned}
& A R_{i t}=\alpha+\beta x_{i t}+\gamma \Delta \hat{q}_{i t}+\delta \Delta \hat{b}_{i t}+\omega \Delta \hat{g}_{i t}+\varphi \Delta \hat{r}_{i t}+e_{i t} \\
& A R_{i t}=\quad \alpha+\beta x_{i t}+\gamma \Delta \hat{q}_{i t}+\gamma_{M} M \Delta \hat{q}_{i t}+\gamma_{H} H \Delta \hat{q}_{i t}+\delta \Delta \hat{b}_{i t} \\
& +\quad \omega \Delta \hat{g}_{i t}+\omega_{M} M \Delta \hat{g}_{i t}+\omega_{H} H \Delta \hat{g}_{i t}+\varphi \Delta \hat{r}_{i t}+e_{i t} \\
& A R_{i t}=\alpha+\beta x_{i t}+\lambda \Delta x_{i t}+e_{i t}
\end{aligned}
$$

Nas equações acima, $A R_{i t}$ é o retorno anormal da firma $i$ no período $t$ calculado da seguinte forma: [Retorno da ação i no ano t] - [Retorno do índice Bovespa no mesmo período do retorno da ação].

As demais variáveis definidas nas equações (6'), (7') e (8') são as mesmas definidas para as equações (6), (7) e (8).

Foram realizadas regressões em pooled e também em painel Fama-Macbeth para os dados com o retorno anormal. Os resultados podem ser observados, respectivamente, nas tabelas 10 e 11 apresentadas a seguir. 
Tabela 7

Resultado das regressões das amostras dos retornos Anormais - pooled

\begin{tabular}{|c|c|c|c|c|c|c|c|}
\hline Variável & Previsão & Modelo (6') & & Modelo (7') & & Modelo (8') & \\
\hline & Valor/Sinal & Coef. & $t$ stat & Coef. & $t$ stat & Coef. & $t$ stat \\
\hline \multirow[t]{11}{*}{ Int. } & $+/-$ & -.08 & $(0.01)$ & -0.09 *** & $(-7.17)$ & $-0.02^{*}$ & $(-1.81)$ \\
\hline & 1 & $0.40^{\text {**** }}$ & $(7.87)$ & $0.40^{* * *}$ & $(7.92)$ & $0.26^{* * * *}$ & $(4.30)$ \\
\hline & + & & & & & 0.06 & $(1.27)$ \\
\hline & + & $0.07 * *$ & $(2.03)$ & -0.01 & $(0.17)$ & & \\
\hline & + & & & $1.31^{*}$ & $(1.89)$ & & \\
\hline & + & & & $0.15^{* *}$ & $(2.41)$ & & \\
\hline & 1 & $0.16^{\text {*** }}$ & $(3.17)$ & $0.16^{* * *}$ & $(3.20)$ & & \\
\hline & + & $0.16^{* * * *}$ & -7.167 & $0.15^{* * *}$ & $(4.53)$ & & \\
\hline & + & & & $0.14 * * *$ & $(2.83)$ & & \\
\hline & + & & & $0.18^{* * * *}$ & $(7.08)$ & & \\
\hline & $\begin{array}{lll}- & \\
-\end{array}$ & -0.00 & $(-0.18)$ & 0 & $(0.27)$ & & \\
\hline $\mathrm{F}$ & & $34.06 * * *$ & & $22.47 * * *$ & & & $16.24 * * *$ \\
\hline$R^{2}$ ajust. & & 19.69 & & 20.33 & & & 6.79 \\
\hline \multicolumn{8}{|c|}{$\begin{array}{l}\Delta \hat{q}_{i t}=\left(q_{i t}-q_{i t-1} B_{i t-1} / V_{i t-1} \text { : é a variação na rentabilidade da firma } i \text { no ano } t \text {, ajustado pela razão }\right. \\
\text { patrimônio líquido e valor de mercado em } t-1 \text {, sendo a rentabilidade definida como o retorno sobre o patrimônio } \\
\text { líquido. }\end{array}$} \\
\hline \multicolumn{8}{|c|}{$\begin{array}{l}\Delta \hat{b}_{i t}=\left[\left(B_{i t}-B_{i t-1}\right) / B_{i t-1}\right]\left(1-B_{i t-1} / V_{i t-1}\right) \text { : é o patrimônio líquido (capital investido) ou } \\
\text { mudança proporcional no patrimônio líquido da firma } i \text { no ano } t \text {, ajustado por um menos o book-to-market } \\
\text { em } t-1 \text {. }\end{array}$} \\
\hline \multicolumn{8}{|c|}{$\begin{array}{l}\Delta \hat{g}_{i t}=\left(g_{i t}-g_{i t-1}\right) B_{i t-1} / V_{i t-1} \text { é a variação da oportunidade de crescimento da firma } i \text { no ano } t, \\
\text { ajustado pelo book-to-market em } t-1 \text {. Neste estudo } g_{i t}=V_{i t} / B_{i t} \text {, ou seja, foi utilizado o market-to-book } \\
\text { ou price-to-book como proxy para crescimento. }\end{array}$} \\
\hline \multicolumn{8}{|c|}{$\begin{array}{l}\Delta \hat{r}_{i t}=\left(r_{i t}-r_{i t-1}\right) B_{i t-1} / V_{i t-1} \text { é a variação da taxa de desconto no ano } t \text { ajustado pelo book-to-market } \\
\text { em } t-1 .\end{array}$} \\
\hline \multicolumn{8}{|c|}{$\begin{array}{l}M \text { e } H \text { : são variáveis dummy para as diferentes rentabilidades, média (um terço médio) e alta (terça parte } \\
\text { superior) da rentabilidade das amostras. } \\
F \text { : Valor da estatística } F \text {. }\end{array}$} \\
\hline
\end{tabular}

No resultado das regressões em pooled para as amostras do retorno anormal observa-se que, em sua grande maioria, os coeficientes são significativos e possuem sinais condizentes com o previsto pelo modelo. No modelo (6') observa-se que a variação da taxa de desconto não é significante. No modelo (7') a variável $\Delta \hat{q}_{i t}$ e a variação da taxa de desconto não são significantes. No modelo (8') a variação do lucro não é significante.

Em relação à magnitude dos coeficientes, observa-se que os resultados encontrados para os retornos anormais são inferiores aos encontrados para os retornos totais, no entanto não são discrepantes.

Os $R^{2}$ ajustados encontrados para os retornos anormais são relativamente inferiores para os modelos (6') e (7') quando comparados com os modelos (6) e (7). Para o modelo (8'), o resultado encontrado não difere muito do resultado encontrado para o modelo (8).

O teste de Vuong (1989) também foi utilizado para comparação dos resultados apresentados pelos modelos (6'), (7') e (8'), que utilizaram o retorno anormal.

Nos testes realizados foram encontrados os seguintes resultados: 
- Comparação entre o modelo (6') e o modelo (7'): $\mathrm{Z}=-1.27$.

- Comparação entre o modelo (6') e o modelo (8'): $Z=5.42$.

- Comparação entre o modelo (7') e o modelo (8'): Z=6.01.

Os testes de Vuong são inconclusivos quando comparados os modelos (6') e (7'). O modelo (8') apresenta menor poder explicativo que os modelos (6) e (7) desenvolvidos por Zhang \& Chen (2007).

Tabela 8

Resultado das regressões das amostras dos retornos anormais - Fama MacBeth

\begin{tabular}{l|c|c|c|c|c|c|c}
\hline Variável & Previsão & Modelo (6') & & Modelo (7') & & Modelo (8') & \\
\hline & Valor/ Sinal & Coef. & $t$ stat & Coef. & $t$ stat & Coef. & $t$ stat \\
\hline Int. & $+/-$ & $-0.13^{* *}$ & $(-2.42)$ & $-0.12^{* *}$ & $(-2.29)$ & -0.04 & $(-0.76)$ \\
\hline & 1 & $0.61^{* * *}$ & $(4.13)$ & $0.62^{* * *}$ & $(3.96)$ & $0.44^{*}$ & $(2.07)$ \\
\hline & + & & & & & 0.02 & $(0.14)$ \\
\hline & + & 0.06 & $(0.87)$ & $0.10^{* *}$ & $(2.73)$ & & \\
\hline & + & & & $1.27^{*}$ & $(2.10)$ & & \\
\hline & + & & & -0.02 & $(-0.12)$ & & \\
\hline & 1 & $0.23^{* *}$ & $(2.75)$ & $0.23^{* *}$ & $(2.62)$ & & \\
\hline & + & $0.31^{* * *}$ & $(5.87)$ & $0.31^{* * *}$ & $(4.75)$ & & \\
\hline & + & & & $0.35^{* * *}$ & $(5.12)$ & & \\
\hline & + & & & $0.47^{* * *}$ & $(6.31)$ & & \\
\hline$F$ & - & 0.00 & $(1.32)$ & 0 & $(0.55)$ & & \\
\hline$R^{2}$ ajust & & $22.68^{* * *}$ & & $58.38^{* * *}$ & & & $12.45^{* * *}$ \\
\hline
\end{tabular}

Nota: $x_{i t}=X_{i, t} / V_{i t-1}$ : é o lucro da firma $i$ no ano $t$ dividido pelo valor de mercado da firma $i$ no ano $t-1$.

$\Delta \hat{q}_{i t}=\left(q_{i t}-q_{i t-1} B_{i t-1} / V_{i t-1}\right.$ : é a variação na rentabilidade da firma $i$ no ano $t$,

ajustado pela razão patrimônio líquido e valor de mercado em $t-1$, sendo a rentabilidade

definida como o retorno sobre o patrimônio líquido.

$\Delta \hat{b}_{i t}=\left[\left(B_{i t}-B_{i t-1}\right) / B_{i t-1}\right]\left(1-B_{i t-1} / V_{i t-1}\right)$ : é o patrimônio líquido (capital investido) ou mudança proporcional no patrimônio líquido da firma $i$ no ano $t$, ajustado por um menos o book-to-market em $t-1$.

$\Delta \hat{g}_{i t}=\left(g_{i t}-g_{i t-1}\right) B_{i t-1} / V_{i t-1}$ é a variação da oportunidade de crescimento da firma $i$ no ano $t$, ajustado pelo book-to-market em $t-1$. Neste estudo $g_{i t}=V_{i t} / B_{i t}$, ou seja, foi utilizado o market-to-book ou price-to-book como proxy para crescimento.

$\Delta \hat{r}_{i t}=\left(r_{i t}-r_{i t-1}\right) B_{i t-1} / V_{i t-1}$ é a variação da taxa de desconto no ano $t$ ajustado pelo book-to-market em $t-1$.

$M$ e $H$ : são variáveis dummy para as diferentes rentabilidades, média (um terço médio) e alta (terça parte superior) da rentabilidade das amostras.

$F$ : Valor da estatística $F$.

$R^{2}$ ajust.: Coeficiente da regressão.

*** indica significância em 1\%, ** indica significância em 5\% e * indica significância em $10 \%$.

Os resultados das regressões utilizando Fama-Macbeth apresentados na tabela 6 para as amostras contendo os resultados anormais dos modelos (6'), (7') e (8') são muito próximos aos encontrados para os modelos (6), (7) e (8), quando submetidos à regressão em pooled e ao Fama-Macbeth, encontrados respectivamente nas tabelas 5, 6 e 7 . O mesmo comportamento é observado para o $R^{2}$ ajustado.

\section{Conclusão}

Este artigo teve como objetivo investigar, com base no modelo proposto por Zhang \& Chen (2007), como a variação do lucro líquido, da rentabilidade, do 
capital investido, das oportunidades de crescimento e da taxa de desconto explicam as variações nos retornos das ações listadas na BOVESPA. Esses resultados foram comparados com um modelo baseado somente em lucro.

Os resultados encontrados nos diferentes testes realizados (pooled, FamaMacbeth e dados em painel) são estaticamente válidos e condizentes com a teoria apresentada, assim como os resultados encontrados no mercado americano, apesar de alguns coeficientes não terem apresentado significância isoladamente em algumas das regressões apresentadas.

A proximidade dos resultados e os coeficientes encontrados entre os diferentes métodos (pooled, Fama-Macbeth e dados em painel) suportam a robustez dos modelos propostos e validam os resultados encontrados.

Quanto à magnitude dos coeficientes das variáveis independentes das regressões, deve-se destacar que foram, em geral, inferiores aos encontrados para o mercado norte-americano por Zhang \& Chen (2007).

Segundo a teoria apresentada, era esperado que os coeficientes do lucro e do capital investido fossem igual a 1. Uma das hipóteses para esse menor reconhecimento do lucro e do capital investido e também para os demais coeficientes pode estar associada à menor eficiência do mercado brasileiro frente ao mercado americano.

Especificamente quanto ao lucro contábil Ball et al. (2000) esperam que essa variável seja mais relevante em mercados como o americano e o inglês, nos quais os investidores não possuem acesso privilegiado às informações e o controle das empresas é mais pulverizado do que em mercados em que existe uma maior concentração em acionistas com acesso diferenciado às informações como no mercado brasileiro.

Quanto ao valor inferior a 1 encontrado para o coeficiente da variável capital investido, pode-se pensar que o mercado interpreta que haverá uma redução nos dividendos pagos quando ocorre um aumento de capital investido, o que pode influenciar no retorno das ações. Esse resultado abordado difere da teoria desenvolvida de que um incremento de capital aumente as expectativas sobre o valor futuro gerado, elevando o valor de mercado da firma.

O $R^{2}$ ajustado encontrado para os modelos (6) e (7) nos testes com os dados do mercado brasileiro é maior dos que foram encontrados no mercado americano. No entanto o valor do $R^{2}$ ajustado para o modelo 8 apresenta um valor menor no mercado brasileiro em relação ao mercado americano.

Os modelos (6) e (7) propostos por Zhang \& Chen (2007) apresentaram maior poder explicativo que o modelo (8) baseado em lucros, o que suporta a afirmação dos autores de que variáveis contábeis adicionais ao lucro possuem poder explicativo no retorno das ações. O modelo (7) apresentou resultados condizentes quanto aos efeitos previstos pela teoria em relação à rentabilidade e à oportunidade de crescimento, no entanto não foi possível identificar que é mais significativo que o modelo (6). 
Mesmo considerando as especificidades que diferenciam o mercado brasileiro do mercado americano (tais como a estrutura legal baseada no direito codificado -code law; emissão da normatização contábil pelo governo ou órgãos ligados ao governo; influência das regras fiscais nas demonstrações contábeis; concentração de capital; baixo nível de enforcement, fontes de financiamento; e tamanho do mercado de capitais), as relações propostas pelo modelo teórico se demonstraram consistentes no mercado brasileiro. Nesse contexto, não houve aceitação da hipótese testada nesta pesquisa de que os retornos das ações negociadas na BOVESPA não podem ser explicados por variáveis contábeis conforme o modelo proposto por Zhang \& Chen (2007).

Os resultados obtidos podem estar associados a uma suposta evolução do mercado brasileiro, tendo em vista algumas alterações no cenário econômico e no ambiente institucional brasileiro, além de alterações no modelo de governança existente ocorridas antes e durante o período avaliado por este estudo.

Entre os possíveis fatos que podem justificar a significância e consistência dos resultados encontrados, pode-se destacar o crescimento do mercado de capitais no período em análise, consubstanciado pelo aumento do número de empresas que emitiram ADRs (American Depositary Receipts), o crescimento do número de negócios realizados na BOVESPA, o aumento da base acionária das empresas brasileiras, a criação de níveis de governança corporativa diferenciados na BOVESPA, a melhoria na qualidade das informações divulgadas pelas empresas, o efeito da privatização de grandes empresas de setores tais como Telefonia, Elétrico, Mineração e Siderurgia além da queda dos indicadores de risco país ao longo dos anos.

\section{Referências}

Ali, Asquid, \& Hwang, Lee-Seok. 2000. Country-Specific Factors Related to Financial Reporting and the Value Relevance of Accounting Data. Journal of Accounting Research, 38, 1-21.

Ball, Ray, \& Brown, Philip. 1968. An Empirical Evaluation of Accounting Income Numbers. Journal of Accounting Research, 6, 159-178.

Ball, Ray, Kothari, S. P., \& Robin, Ashok. 2000. The Effect on International Institutional Factors on Properties of Accounting Earnings. Journal of Accounting and Economics, 29, 67-97.

Beaver, William. 1968. The Information Content of Annual Earnings Announcements. Journal of Accounting Research Supplement, 6, 67-92.

Beaver, William. 1998. Financial Reporting: An Accounting Revolution. 3rd edn. New Jersey: Prentice Hall.

Berger, Philip, Ofek, Eli, \& Swary, Itzhak. 1996. Investor Valuation of the Abandonment Option. Journal of Financial Economics, 45, 1-31. 
Brennan, Michael, \& Schartz, Eduardo. 1985. Evaluating Natural Resources Investments. Journal of Business, 58, 135-157.

Burgstahler, David, \& Dichev, Ilia. 1997. Earnings, Adaptation, and Equity Value. The Accounting Review, 73, 187-215.

Durnev, Art, \& Kim, E. Ham. 2005. To Steal or Not Steal: Firm Attributes, Legal Environment, and Valuation. Journal of Finance, 60, 1461-1493.

Easton, Peter, \& Harris, Trevor. 1991. Earnings as an Explanatory Variable for Returns. Journal of Accounting Research, 29, 19-36.

Ely, Kirsten, \& Waymire, Gregory. 1999. Accounting Standard-Setting Organizations and Earnings Relevance: Longitudinal Evidence from NYSE Common Stocks. Journal of Accounting Research, 37, 293-318.

Fama, Eugene. 1970. Efficient Capital Markets: A Review Theory and Empirical Work. Journal of Finance, 25.

Fama, Eugene, \& Macbeth, James. 1973. Risk, Return and Equilibrium: Empirical Tests. Journal of Political Economy, 81, 607-636.

Feltham, Gerald, \& Ohlson, James. 1995. Valuation and Clean Surplus Accounting for Operating and Financing Activities. Contemporary Accounting Research, 11, 689-731.

Feltham, Gerald, \& Ohlson, James. 1996. Uncertain Resolution and the Theory of Depreciation Measurement. Journal of Accounting Research, 34, 209-234.

Francis, Jennifer, \& Shipper, Katherine. 1999. Have Financial Statements Lost their Relevance? Journal of Accounting Research, 37, 319-352.

Galdi, Fernando C. 2008. Estratégias de Investimento Em Ações Baseadas Na Análise de Demonstrações Contábeis: É Possível Prever O Sucesso? São Paulo. Tese (doutorado) - Faculdade de Economia, Administração e Contabilidade da Universidade de São Paulo: 129p.

Galdi, Fernando C., \& Lopes, Alexandro B. 2007. Does Financial Statement Analysis Generate Abnormal Returns Under Extremely Adverse Conditions? Sétimo Encontro Brasileiro de Finanças, São Paulo, Sbfin.

Gazeta Mercantil. 2000. O Mercado Paga Pouco Para Ter Direito a Voto. São Paulo, p. C1, 22 de Dezembro.

La Porta, Rafael, Lopes-de Silanez, Florencio, Shleifer, Andrei, \& Vishny, Robert. 1997. Legal Determinants of External Finance. Journal of Finance, 52, 11311150.

156 Revista Brasileira de Finanças, Rio de Janeiro, Vol. 9, N. 1, 131-157, 2011 
Lev, Baruch, \& Zarowin, Paul. 1999. The Boundaries of Financial Reporting and How to Extend Them. Journal of Accounting Research, 37, 353-385.

Lopes, Alexandro B. 2005. Financial Accounting in Brazil: An Empirical Examination. Latin American Business Review, 6, 45-68.

Meyers, Stewart. 1977. Determinants of Corporate Borrowing. Journal of Financial Economics, 5, 147-175.

Miller, Merton, \& Modigliani, Franco. 1961. Dividend Policy, Growth, and the Valuation of Shares. Journal of Business, 34, 411-433.

Ohlson, James. 1995. Earnings, Book Values, and Dividends in Equity Valuation. Contemporary Accounting Research, 11, 661-687.

Palepu, Krishna, Healy, Paul, \& Bernard, Vicent. 2004. Business Analysis \& Valuation. 3 edn. Thomson.

Penman, Stephen. 2007. Financial Statements Analysis and Security Valuation. New York: McGraw-Hill.

Petersen, Mitchell. 2009. Estimating Standard Errors in Financial Panel Data Sets: Comparing Approaches. Review of Financial Studies, 22, 435-480.

Pincus, Morton, Rajgopal, Shivaram, \& Venkatachalam, Mohan. 2007. The Accrual Anomaly: International Evidence. Accounting Review, 82, 169-203.

Sarlo, Alfredo, Neto. 2004. A Relação Dos Preços Das Ações À Divulgação Dos Resultados Contábeis: Evidência Empírica Sobre a Capacidade Informacional Da Contabilidade No Mercado Acionário Brasileiro. Dissertação de Mestrado - FUCAPE - Vitória-ES.

Shleifer, Andrei, \& Vishny, Robert. 1997. A Survey of Corporate Governance. Journal of Finance, 52, 737-783.

Vuong, Quang. 1989. Likelihood Ratio Tests for Model Selection and Non-Nested Hypotheses. Econometrica, 57, 307-334.

Zhang, Guochang. 2000. Accounting Information, Capital Investments Decisions, and Equity Valuation: Theory and Empirical. Journal of Accounting Research, 38, 271-295.

Zhang, Guochang, \& Chen, Peter. 2007. How Do Accounting Variables Explain Stock Price Movements? Theory and Evidence. Journal of Accounting and Economics, 43, 219-244. 